\title{
OPEN Yield and quality of brown rice noodles processed from early-season rice grains
}

\author{
Min Huang ${ }^{凶}$, Zhengwu Xiao, Jiana Chen \& Fangbo Cao
}

Producing rice noodles using early-season rice grains is a way to bypass difficulties in marketing earlyseason rice that does not meet consumer preference for soft-textured rice. In recent years, brown rice foods including noodles have attracted great attention due to their health and nutritional benefits. This study was conducted to evaluate the yield and quality of brown rice noodles processed from two early-season rice cultivars. Results showed that the yield of brown rice noodles was $12-19 \%$ higher than that of white rice noodles. Although the cooked break rate and cooking loss rate were $5-10 \%$ higher in brown rice noodles compared to white rice noodles, both were within an acceptable range for brown rice noodles. Cooked brown rice noodles had 21-27\% lower hardness and chewiness than cooked white rice noodles, though differences in the elasticity parameters springiness, cohesiveness, and resilience were not significant or were inconsistent between cooked brown and white rice noodles. These results suggest that it is feasible to process early-season rice to produce brown rice noodles of desirable yield and quality.

Rice is the most important food crop in China, as more than $65 \%$ of the population relies on it as a staple food ${ }^{1}$. The development of double-season rice cropping systems (i.e., successively growing early- and late-season rice within a year) in southern China is critical in ensuring food security in China ${ }^{2}$, where the arable land per capita is far below the world average ${ }^{3}$. However, the planting area of double-season rice, particularly early-season rice, has decreased sharply in recent decades ${ }^{4}$. The decrease in planting area of early-season rice is related to improved living standards in China, which has led to demand for and consumption of high-quality rice, especially rice with flavor desired by consumers ${ }^{5}$. Namely, early-season rice generally has a high amylose content, which does not meet consumer preference for rice with low amylose content and soft texture ${ }^{6}$.

Due to concerns about the negative impact of the decreasing planting area of early-season rice on national food security, the Chinese government is trying to reverse the trend of early-season rice planting area decreasing by promoting the sale and consumption of early-season rice. Early-season rice can not only be directly consumed as cooked rice but can also be used to make various food products ${ }^{7}$. Early-season rice with high amylose content is suitable for manufacturing rice noodles ${ }^{8}$, which are a popular and traditional staple food item in southern China'. Some southern provinces of China such as Hunan have begun to develop special early-season rice for producing rice noodles in order to effectively market early-season rice.

Rice noodles have been produced using only white rice (milled rice) in China, because convention suggests that the taste of brown rice noodles is not accepted by consumers ${ }^{10,11}$. But in fact, most consumers do not have experience with eating brown rice noodles and have no preconceived notions about them. In recent years, whole grain (including brown rice) foods have attracted great attention due to their health benefits, such as reducing the risk of non-communicable diseases like cardiovascular disease, cancer, and diabetes ${ }^{12,13}$, which are of increasing concern both nationally and globally due to their high mortality rates ${ }^{14}$. In addition, since brown rice undergoes a low degree of milling, milling loss can be reduced, thereby preserving the nutritional composition of rice, such as fat, protein, phosphorus, calcium, and B vitamins ${ }^{15}$.

In this study, we determined the milling recovery rate, starch content, and paste characteristics of brown and white rice as well as the yield, texture, and cooking properties of brown and white rice noodles processed from two early-season rice cultivars. Our objectives were to evaluate the yield and quality of brown rice noodles and provide a basis for further development and utilization of early-season rice.

Crop and Environment Research Center for Human Health, Key Laboratory of Ministry of Education for Crop Physiology and Molecular Biology, Hunan Agricultural University, Changsha 410128, China. ${ }^{\varpi}$ email: mhuang@ hunau.edu.cn 


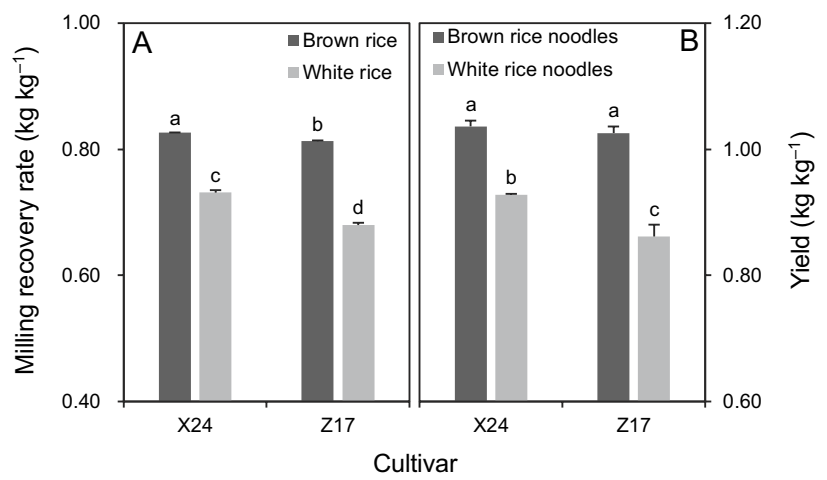

Figure 1. Milling recovery rate of brown and white rice $(\mathbf{A})$ and yield of brown and white rice noodles $(\mathbf{B})$ processed from two rice cultivars, Xiangzaoxian 24 (X24) and Zhongjiazao 17 (Z17). Data are mean \pm SE $(n=3)$. Bars sharing the same lowercase letters are not significantly different at the 0.05 probability level.

\begin{tabular}{|l|l|l|l|}
\hline Cultivar & Noodle & Total starch content $\left(\mathrm{g} \mathrm{g}^{-1}\right)$ & Amylose content $\left(\mathrm{g} \mathrm{g}^{-1}\right)$ \\
\hline \multirow{2}{*}{ X24 } & Brown & $0.638 \pm 0.002 \mathrm{~d}$ & $0.219 \pm 0.004 \mathrm{c}$ \\
\cline { 2 - 4 } & White & $0.708 \pm 0.005 \mathrm{~b}$ & $0.243 \pm 0.002 \mathrm{~b}$ \\
\hline \multirow{2}{*}{ Z17 } & Brown & $0.677 \pm 0.001 \mathrm{c}$ & $0.243 \pm 0.002 \mathrm{~b}$ \\
\cline { 2 - 4 } & White & $0.733 \pm 0.005 \mathrm{a}$ & $0.275 \pm 0.005 \mathrm{a}$ \\
\hline
\end{tabular}

Table 1. Total starch and amylose content in brown and white rice flours processed from two rice cultivars, Xiangzaoxian 24 (X24) and Zhongjiazao 17 (Z17). Data are mean \pm SE $(n=3)$. Within a column, data sharing the same lowercase letters are not significantly different at the 0.05 probability level.

\begin{tabular}{|c|c|c|c|c|c|c|c|c|c|}
\hline \multirow[b]{2}{*}{ Cultivar } & \multirow[b]{2}{*}{ Flour } & \multicolumn{6}{|c|}{ Viscosity (cP) } & \multirow{2}{*}{$\begin{array}{l}\text { Time to peak } \\
\text { viscosity } \\
(\mathrm{min})\end{array}$} & \multirow{2}{*}{$\begin{array}{l}\text { Paste } \\
\text { temperature } \\
\left({ }^{\circ} \mathrm{C}\right)\end{array}$} \\
\hline & & Peak & Trough & Breakdown & Final & Setback & Consistency & & \\
\hline \multirow{2}{*}{$\mathrm{X} 24$} & Brown & $2002 \pm 43 b$ & $1640 \pm 42 c$ & $362 \pm 3 c$ & $3445 \pm 44 \mathrm{c}$ & $1443 \pm 18 \mathrm{a}$ & $1805 \pm 21 \mathrm{a}$ & $6.31 \pm 0.02 \mathrm{a}$ & $87.1 \pm 0.0 \mathrm{a}$ \\
\hline & White & $2991 \pm 6 a$ & $2416 \pm 86 a$ & $575 \pm 80 \mathrm{~b}$ & $4188 \pm 41 \mathrm{a}$ & $1197 \pm 35 b$ & $1771 \pm 62 a$ & $6.22 \pm 0.08 \mathrm{a}$ & $80.8 \pm 0.0 \mathrm{~b}$ \\
\hline \multirow{2}{*}{$\mathrm{Z} 17$} & Brown & $1866 \pm 36 \mathrm{~b}$ & $1343 \pm 30 \mathrm{~d}$ & $523 \pm 17 \mathrm{~b}$ & $2796 \pm 67 d$ & $930 \pm 32 c$ & $1452 \pm 46 b$ & $5.87 \pm 0.04 \mathrm{~b}$ & $81.0 \pm 0.3 \mathrm{~b}$ \\
\hline & White & $2891 \pm 66 a$ & $2098 \pm 62 b$ & $793 \pm 10 a$ & $3658 \pm 61 b$ & $766 \pm 13 \mathrm{~d}$ & $1560 \pm 21 b$ & $5.91 \pm 0.02 b$ & $80.0 \pm 0.0 \mathrm{c}$ \\
\hline
\end{tabular}

Table 2. Paste properties of brown and white rice flours processed from two rice cultivars, Xiangzaoxian 24 (X24) and Zhongjiazao 17 (Z17). Data are mean \pm SE $(n=3)$. Within a column, data sharing the same lowercase letters are not significantly different at the 0.05 probability level.

\section{Results}

There were significant differences between milling recovery rates of brown and white rice and between yields of brown and white rice noodles for both X24 and Z17 (Fig. 1A,B). The milling recovery rates of brown rice were respectively $13 \%$ and $20 \%$ higher than those of white rice for X24 and Z17 (Fig. 1A). The yields of brown rice noodles were higher than those of white rice noodles by 12\% in X24 and 19\% in Z17 (Fig. 1B).

The differences in total starch and amylose contents were significant between brown and white rice flours for both X24 and Z17 (Table 1). Total starch contents were 10\% and 8\% lower in brown rice flour than in white rice flour for X24 and Z17, respectively. Brown rice flour had lower amylose content than white rice flour by $10 \%$ for X24 and by $12 \%$ for Z17.

There were significant differences in all paste properties, except for consistency viscosity and time to peak viscosity, between brown and white rice flours for both X24 and Z17 (Table 2). Peak, trough, breakdown, and final viscosities were lower in brown rice flour than in white rice flour by $18-37 \%$ for X24 and by $24-36 \%$ for Z17, while setback viscosity was higher in brown rice flour than in white rice flour by $21 \%$ for both X 24 and Z17. Paste temperatures were respectively 6.3 and $1.0{ }^{\circ} \mathrm{C}$ higher for brown rice flour than for white rice flour for X24 and Z17.

There were significant differences in cooking properties between brown and white rice noodles for both X24 and Z17 (Table 3). Cooked break rate was $9 \%$ and 10\% higher in brown rice noodles than in white rice noodles for X24 and Z17, respectively. Cooking loss rate was higher in brown rice noodles than in white rice noodles by $5 \%$ for X24 and by $7 \%$ for Z17. 


\begin{tabular}{|l|l|l|c|}
\hline Cultivar & Noodle & Cooked break rate (\%) & Cooking loss rate (\%) \\
\hline \multirow{2}{*}{ X24 } & Brown & $11.1 \pm 4.0 \mathrm{a}$ & $11.7 \pm 1.4 \mathrm{a}$ \\
\cline { 2 - 4 } & White & $2.2 \pm 2.2 \mathrm{~b}$ & $6.8 \pm 0.3 \mathrm{~b}$ \\
\hline \multirow{2}{*}{ Z17 } & Brown & $11.1 \pm 4.4 \mathrm{a}$ & $12.5 \pm 0.4 \mathrm{a}$ \\
\cline { 2 - 4 } & White & $1.1 \pm 1.1 \mathrm{~b}$ & $5.4 \pm 0.2 \mathrm{~b}$ \\
\hline
\end{tabular}

Table 3. Cooking properties of brown and white rice noodles processed from two rice cultivars, Xiangzaoxian 24 (X24) and Zhongjiazao 17 (Z17). Data are mean \pm SE $(n=3)$. Within a column, data sharing the same lowercase letters are not significantly different at the 0.05 probability level.

\begin{tabular}{|l|l|l|l|l|l|l|}
\hline Cultivar & Noodle & Hardness $(\mathrm{g})$ & Chewiness $(\mathrm{g})$ & Springiness (\%) & Cohesiveness (\%) & Resilience (\%) \\
\hline \multirow{2}{*}{ X24 } & Brown & $2056 \pm 83 \mathrm{bc}$ & $1381 \pm 47 \mathrm{c}$ & $87.7 \pm 0.6 \mathrm{~b}$ & $76.7 \pm 0.4 \mathrm{~b}$ & $50.1 \pm 0.5 \mathrm{~b}$ \\
\cline { 2 - 7 } & White & $2744 \pm 279 \mathrm{a}$ & $1901 \pm 126 \mathrm{a}$ & $89.2 \pm 1.4 \mathrm{ab}$ & $78.2 \pm 1.6 \mathrm{ab}$ & $54.0 \pm 1.1 \mathrm{ab}$ \\
\hline \multirow{2}{*}{ Z17 } & Brown & $1740 \pm 103 \mathrm{c}$ & $1200 \pm 78 \mathrm{~d}$ & $88.6 \pm 0.5 \mathrm{ab}$ & $77.8 \pm 0.2 \mathrm{ab}$ & $51.7 \pm 0.4 \mathrm{~b}$ \\
\cline { 2 - 7 } & White & $2197 \pm 217 \mathrm{~b}$ & $1614 \pm 114 \mathrm{~b}$ & $90.9 \pm 0.6 \mathrm{a}$ & $81.3 \pm 1.9 \mathrm{a}$ & $57.9 \pm 1.6 \mathrm{a}$ \\
\hline
\end{tabular}

Table 4. Texture profiles of brown and white rice noodles processed from two rice cultivars, Xiangzaoxian 24 (X24) and Zhongjiazao 17 (Z17). Data are mean \pm SE $(n=3)$. Within a column, data sharing the same lowercase letters are not significantly different at the 0.05 probability level.

The differences in hardness and chewiness were significant between cooked brown and white rice noodles for both X24 and Z17 (Table 4). Cooked brown rice noodles had 25\% and 21\% lower hardness than cooked white rice noodles for X24 and Z17, respectively. Chewiness was lower in cooked brown rice noodles than in cooked white rice noodles by $27 \%$ for X24 and by $26 \%$ for Z17. Differences in springiness and cohesiveness were not significant between cooked brown and white rice noodles for either X24 or Z17. There was also no significant difference in resilience between cooked brown and white rice noodles for X24, whereas for Z17 cooked brown rice noodles had $6 \%$ lower resilience than cooked white rice noodles.

\section{Discussion}

There are few studies comparing the yield of rice noodles processed from brown and white rice, likely because the result is easy to predict. As expected, the higher milling recovery rate of brown rice compared to white rice led to a higher yield of brown rice noodles than white rice noodles in the present study. Furthermore, this study showed that the magnitude of the difference in the milling recovery rate between brown and white rice was comparable to that of the difference in the yield between brown and white rice noodles. This result indicates that the advantage in milling recovery rate of brown rice compared to white rice can be maintained in producing rice noodles. In addition, the results of this study showed that the magnitude of the differences in the milling recovery rate and yield between brown and white rice noodles varied with cultivars: both values were lower in $\mathrm{X} 24$ than in Z17. This outcome highlights that the milling property should be listed as a criterion for selecting rice cultivars to produce rice noodles.

Brown rice noodles had poorer cooking quality (higher cooked break rate and cooking loss rate) than white rice noodles. However, both the cooked break rate (about 11\%) and the cooking loss rate (about 12\%) of brown rice noodles in this study are not high and are within an acceptable range of less than $15 \%{ }^{16}$. The poorer cooking quality of brown rice noodles than white rice noodles was attributable to reduced paste viscosities in brown rice flour compared to white rice flour. This is somewhat supported by Bhattachrya et al. ${ }^{17}$, who observed that the cooking loss rate of rice noodles was negatively related to paste viscosities of rice flours. It is well-known that paste properties of rice flour are closely associated with its composition. In particular, Saleh et al. ${ }^{18}$ observed that addition of rice bran into rice flours significantly reduced paste viscosities. Geng et al. ${ }^{10}$ found that peak, trough, and final viscosities were positively related to total starch content in rice flours. Therefore, in this study, the reductions in paste viscosities in brown rice flour compared to white rice flour were attributable to retained rice bran and reduced total starch content.

Cooked brown rice noodles had a softer texture (lower hardness and chewiness) than cooked white rice noodles. This texture property of cooked brown rice noodles should be acceptable to Chinese consumers, who prefer soft-textured rice 6 . It has been long recognized that amylose content is an important factor in determining the texture of cooked rice and rice products ${ }^{19,20}$. Although high amylose content is essential for manufacturing rice noodles, within the range of amylose content that is suitable for manufacturing rice noodles, a lower amylose content can lead to a softer texture of rice noodles. Hence, in this study, the softer texture of cooked brown rice noodles compared to cooked white rice noodles could be partially explained by the lower amylose content in brown rice flour than in white rice flour. More recently, Geng et al. ${ }^{10}$ observed that the chewiness of cooked rice noodles was positively related to total starch content but negatively related to damaged starch, protein, lipid, and dietary fiber contents in rice flours. Hence, in the present study, the lower total starch content in brown 

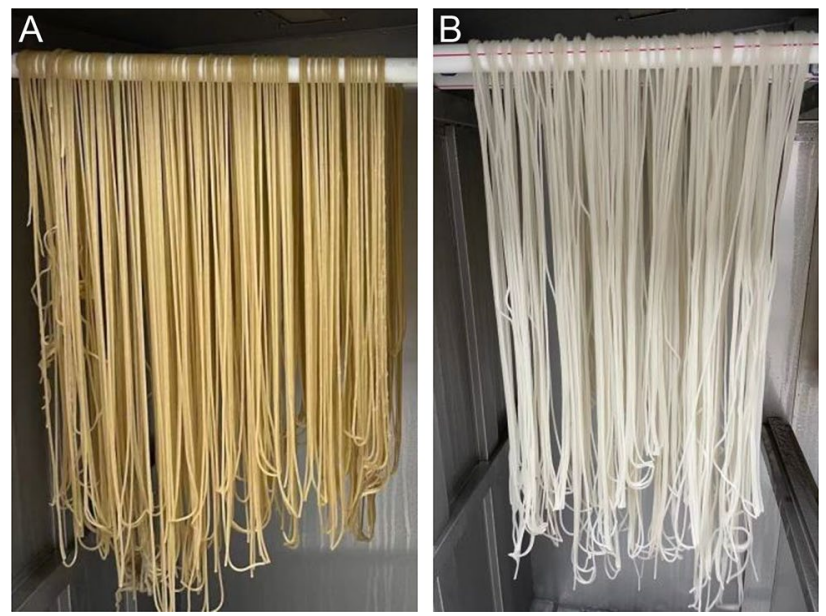

Figure 2. Images showing the brown (A) and white rice noodles (B) processed in this study.

rice flour than in white rice flour also resulted in lower chewiness for cooked brown rice noodles compared to cooked white rice noodles.

Although this study did not determine damaged starch, protein, lipid, and dietary fiber contents in rice flours, these ingredients are generally higher in brown rice than in white rice due to lower milling degree ${ }^{21}$. Therefore, the lower milling degree in this study is likely also responsible for the lower chewiness of cooked brown rice noodles compared to cooked white rice noodles. This can be confirmed in future studies by directly comparing damaged starch, protein, lipid, and dietary fiber contents between brown and white rice noodles. In addition, this study showed that there was no significant or consistent difference in elasticity parameters (springiness, cohesiveness, and resilience) between cooked brown and white rice noodles. The inconsistent difference in resilience between cooked brown and white rice noodles across cultivars highlights that the texture quality of brown rice noodles could be improved through cultivar selection.

Taken together, this study suggests that it is feasible to process early-season rice to produce brown rice noodles in terms of yield and quality, and more cultivars should be included in future investigations to obtain more useful information to improve yield and quality of brown rice noodles.

\section{Methods}

Rice grains of two rice cultivars, Xiangzaoxian 24 (X24) and Zhongjiazao 17 (Z17), were collected from the research farm of the Crop and Environment Research Center $\left(28^{\circ} 09^{\prime} \mathrm{N}, 113^{\circ} 37^{\prime} \mathrm{E}, 43 \mathrm{~m}\right.$ asl), at Hunan Agricultural University, China in the early-rice growing season in 2020. The two cultivars were selected because they have high amylose content in rice grains and are widely used to manufacture rice noodles in southern China. The use of plants in the present study complies with international, national and/or institutional guidelines.

Three samples (replicates) of $100 \mathrm{~g}$ of rice grains were de-hulled to brown rice and then half of the brown rice was polished to white rice for each cultivar. Samples were weighed to calculate the milling recovery rates of brown and white rice by separately dividing the brown and white rice weight by the grain weight, followed by adjusting moisture content to $0.135 \mathrm{~g} \mathrm{H}_{2} \mathrm{O} \mathrm{g}^{-1}$.

About $5 \mathrm{~g}$ of brown and white rice flours (filtered through $100 \mathrm{mesh}$ ) were prepared for each sample to determine starch content and paste properties. Total starch content was determined using an auto digital polarimeter (P850 Pro, Jinan Hanon Instruments Co., Ltd., Jinan, China). Amylose content was measured with the iodine colorimetric method according to the procedure described by Huang et al. ${ }^{22}$. Total starch and amylose contents were adjusted to a moisture content of $0.135 \mathrm{~g} \mathrm{H}_{2} \mathrm{O} \mathrm{g}^{-1}$. The paste properties (peak, trough, breakdown, final, setback, and consistency viscosities, time to peak viscosity, and paste temperature) were determined using a Rapid Visco Analyzer (RVA-Super 4, Newport Scientific Pty Ltd., Warriewood, Australia).

Six samples of grains were processed to three brown and three white rice samples ( $500 \mathrm{~g}$ per sample) to produce rice noodles. In brief, rice samples were soaked for $10 \mathrm{~h}$ at room temperature and then put in an automatic rice noodle-manufacturing machine (5-MFD15B, Hunan Fenshifu Machinery Technology Co., Ltd., Loudi, China) to produce rice noodles with a diameter of $3 \mathrm{~mm}$ (Fig. 2A,B). Rice noodles were weighed after they were placed in a self-contained optimization box of the rice noodle-manufacturing machine for $8 \mathrm{~h}$ to allow the water to be evenly distributed in the noodles. The yield of rice noodles was calculated by dividing the rice noodle weight by the grain weight.

Thirty noodles with a length of $20 \mathrm{~cm}$ were weighed and then boiled in distilled water for $7 \mathrm{~min}$ to determine cooking properties (cooked break rate and cooking loss rate) and texture profiles (hardness, springiness, cohesiveness, resilience, and chewiness). Broken noodles were counted to calculate the cooked break rate (number of broken noodles/total number of noodles $\times 100$ ). Solids lost to the cooking water were oven-dried at $105^{\circ} \mathrm{C}$ to a constant weight to calculate the cooking loss rate according to the formula described by Tong et al..$^{23}$. The texture profiles of cooked rice noodles were determined using a texture analyzer (Rapid $\mathrm{TA}^{+}$, Shanghai Tengba Instrument Technology Co. Ltd., Shanghai, China). 
Data were subjected to analysis of variance followed by the LSD test at the 0.05 probability level (Statistix 8.0, Analytical Software, Tallahassee, Florida, USA).

\section{Data availability}

All data generated or analysed during this study are included in the article.

Received: 25 April 2021; Accepted: 7 September 2021

Published online: 21 September 2021

\section{References}

1. Huang, M. \& Zou, Y. Integrating mechanization with agronomy and breeding to ensure food security in China. Field Crops Res. 224, 22-27 (2018).

2. Deng, N. et al. Closing yield gap for rice self-sufficiency in China. Nat. Commun. 10, 1725 (2019).

3. Han, M. \& Chen, G. Global arable land transfers embodied in Mainland China's foreign trade. Land Use Policy 70, 521-534 (2018).

4. Peng, S. Dilemma and way-out of hybrid rice during the transition period in China. Acta Agron. Sin. 42, 313-319 (2016).

5. Huang, M. \& Hu, L. Low glycemic index: The next target for rice production in China?. J. Integr. Agric. 20, 1727-1729 (2021).

6. Yin, X. et al. Performance of soft rice (Oryza sativa L.) grown in early season in China. Phyton-Int. J. Exp. Bot. 89, 97-102 (2020).

7. Jeong, J., Kim, E. C., Venkatanagappa, S. \& Lee, J. Review of rice: Production, trade, consumption, and future demand in Korea and worldwide. Korean J. Crop Sci. 62, 157-165 (2017).

8. Low, Y. K., Effarizah, M. E. \& Cheng, L. H. Factors influencing rice noodles qualities. Food Rev. Int. 36, 781-794 (2020).

9. Li, Y., Liang, J. F., Yang, M. Y., Chen, J. Y. \& Han, B. Z. Traditional Chinese rice noodles: History, classification, and processing methods. Cereal Foods World 60, 123-127 (2015).

10. Geng, D. et al. Effects of slight milling combined with cellulase enzymatic treatment on the textural and nutritional properties of brown rice noodles. LWT-Food Sci. Technol. 128, 109520 (2020).

11. Wu, N. et al. Nutritional and cooking quality improvement of brown rice noodles prepared with extruded rice bran. Cereal Chem. 98, 346-354 (2020).

12. Aune, D. et al. Whole grain consumption and risk of cardiovascular disease, cancer, and all cause and cause specific mortality: Systematic review and dose-response meta-analysis of prospective studies. BMJ 353, i2716 (2016).

13. Chanson-Rolle, A. et al. Systematic review and meta-analysis of human studies to support a quantitative recommendation for whole grain intake in relation to type 2 diabetes. PLoS ONE 10, e0131377 (2015).

14. Budreviciute, A. et al. Management and prevention strategies for non-communicable diseases (NCDs) and their risk factors. Front. Public Health 8, 574111 (2020).

15. Vetha Varshini, P., Azhagu Sundharam, K. \& Vijay Praveen, P. Brown rice-Hidden nutrients. J. Biosci. Technol. 4, 503-507 (2013).

16. Jiao, A. et al. Structural properties of rice flour as affected by the addition of pea starch and its effects on textural properties of extruded rice noodles. Int. J. Food Prop. 23, 809-819 (2020).

17. Bhattachrya, M., Zee, S. Y. \& Corke, H. Physicochemical properties related to quality of rice noodles. Cereal Chem. 76, 861-867 (1999).

18. Saleh, M., Abuwaar, Z., Akash, M. W. \& Al-Dabbas, M. Effect of stabilized rice bran fractions on the formation of rice flour pasting properties. Cereal Chem. 91, 603-609 (2014).

19. Yu, S., Ma, Y. \& Sun, D. Impact of amylose content on starch retrogradation and texture of cooked rice during storage. J. Cereal Sci. 50, 139-144 (2009).

20. Aoki, N., Umemoto, T., Hamada, S., Suzuki, K. \& Suzuki, Y. The amylose content and amylopectin structure affect the shape and hardness of rice bread. J. Appl. Glycosci. 59, 75-82 (2012).

21. Saleh, A. S. M., Wang, P., Wang, N., Yang, L. \& Xiao, Z. Brown rice versus white rice: Nutritional quality, potential health benefits, development of food products, and preservation technologies. Compr. Rev. Food Sci. Food Saf. 18, 1070-1096 (2019).

22. Huang, M., Jiang, L., Zou, Y. \& Zhang, W. On-farm assessment of effect of low temperature at seedling stage on early-season rice quality. Field Crops Res. 141, 63-68 (2013).

23. Tong, L. et al. Effects of semidry flour milling on the quality attributes of rice flour and rice noodles in China. J. Cereal Sci. 62, $45-49$ (2015).

\section{Acknowledgements}

This study was supported by the National Key R\&D Program of China (2016YFD0300509). The authors thank other members of the Crop and Environment Research Center for their help with this study.

\section{Author contributions}

M.H. conceived the experiment. Z.X., J.C., and F.C. performed the experiment. M.H. analysed the data and wrote the manuscript. All authors reviewed the manuscript.

\section{Competing interests}

The authors declare no competing interests.

\section{Additional information}

Correspondence and requests for materials should be addressed to M.H.

Reprints and permissions information is available at www.nature.com/reprints.

Publisher's note Springer Nature remains neutral with regard to jurisdictional claims in published maps and institutional affiliations. 
(c) (i) Open Access This article is licensed under a Creative Commons Attribution 4.0 International cc) License, which permits use, sharing, adaptation, distribution and reproduction in any medium or format, as long as you give appropriate credit to the original author(s) and the source, provide a link to the Creative Commons licence, and indicate if changes were made. The images or other third party material in this article are included in the article's Creative Commons licence, unless indicated otherwise in a credit line to the material. If material is not included in the article's Creative Commons licence and your intended use is not permitted by statutory regulation or exceeds the permitted use, you will need to obtain permission directly from the copyright holder. To view a copy of this licence, visit http://creativecommons.org/licenses/by/4.0/.

(C) The Author(s) 2021 